\section{Commentary: Finding a solution to the problem: Innovation at its finest}

\author{
Francis D. Pagani, MD, PhD
}

Extracorporeal membrane oxygenation (ECMO) has become an increasingly frequent and invaluable modality to support patients with cardiac and/or respiratory failure. ${ }^{1}$ One of the major attributes of ECMO is its flexibility to provide circulatory and respiratory support using a variety of cannulation strategies that can accommodate different clinical scenarios or address or adapt to clinical complications associated with ECMO use, such as limb ischemia or North-South syndrome. $^{2}$ Further, more prolonged support durations are frequently being used, particularly for respiratory support, where consideration for a cannulation strategy that permits ambulation during ECMO support is paramount. ${ }^{3}$

In this issue of the Journal, Orozco-Hernandez and colleagues ${ }^{4}$ describe the use of ECMO support in a patient following a bilateral lung transplant complicated initially by right-sided circulatory and respiratory failure with a previous history of right internal jugular vein and superior vena cava thrombosis. Initial cardiopulmonary support was provided with venoarterial ECMO using a 15-French arterial cannula and 21-French multistage venous catheter placed in the right common femoral artery and vein, respectively. Following the development of right lower-limb ischemia and recovery of heart function, the patient had the arterial cannula removed and venovenous (VV)-ECMO support initiated. Due to the history of superior vena cava occlusion, the venous catheter in the right common femoral vein was removed and replaced with a ProtekDuo catheter (TandemLife, Inc, Pittsburgh, Pa) positioned with the first set of ports for proximal inflow in the inferior vena cava and the second

From the Department of Cardiac Surgery, University of Michigan, Ann Arbor, Mich. Disclosures: The author reported no conflicts of interest.

The Journal policy requires editors and reviewers to disclose conflicts of interest and to decline handling or reviewing manuscripts for which they may have a conflict of interest. The editors and reviewers of this article have no conflicts of interest.

Received for publication June 21, 2021; revisions received June 21, 2021; accepted for publication June 30, 2021; available ahead of print July 3, 2021.

Address for reprints: Francis D. Pagani, MD, PhD, Department of Cardiac Surgery, 5161 Cardiovascular Center, SPC 5864, University of Michigan, 1500 East Medical Center Dr, Ann Arbor, MI 48109 (E-mail: fpagani@umich.edu).

JTCVS Techniques 2021;9:202-3

2666-2507

Copyright (C 2021 The Author(s). Published by Elsevier Inc. on behalf of The American Association for Thoracic Surgery. This is an open access article under the CC BY-NC-ND license (http://creativecommons.org/licenses/by-nc-nd/4.0/).

https://doi.org/10.1016/j.xjtc.2021.06.042

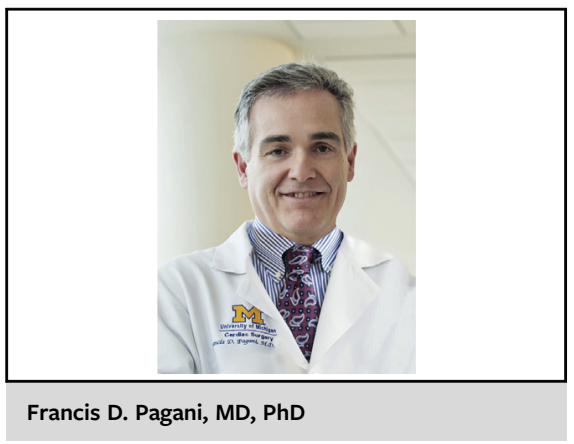

CENTRAL MESSAGE

Venovenous extracorporeal membrane support was achieved using a dual lumen venous catheter placed via the right common femoral vein that permitted ambulation during ECMO support.

set of ports of the distal outflow positioned in the inferior vena cava/right atrial junction. Importantly, using this cannulation strategy, the author and team were able to ambulate the patient with the cannula positioned in the right common femoral vein and provide prolonged VV-ECMO support. Support was successfully weaned on the 49th postoperative day.

This case report illustrates an innovative approach to a challenging clinical scenario in which the providers needed to address several important issues, including limb ischemia and the need to promote ambulation. By astutely recognizing or evaluating for myocardial recovery, the authors were able to switch from venoarterial ECMO to VVECMO support alone using a dual lumen venous catheter. This strategy addressed the limb ischemia, and additionally, permitted the authors to initiate physical rehabilitation and promote ambulation. The key to the success of this strategy was obtaining and maintaining optimal positioning of the dual lumen catheter within the inferior vena cava to prevent recirculation. Although the ProtekDuo catheter is designed for placement via the right internal jugular vein, the authors demonstrated the successful application of this technology to cannulation of the common femoral vein.

\section{References}

1. Guglin M, Zucker MJ, Bazan V, Bozkurt B, El Banayosy A, Estep JD, et al. Venoarterial ECMO for adults: JACC scientific expert panel. J Am Coll Cardiol. 2019;73:698-716. 
2. Makdisi G, Wang IW. Extra corporeal membrane oxygenation (ECMO) review of a lifesaving technology. J Thorac Dis. 2015;7:E166-76.

3. Lindholm JA. Ambulatory veno-venous extracorporeal membrane oxygenation. J Thorac Dis. 2018;10(suppl 5):S670-3.
4. Orozco-Hernandez EJ, Muñoz-Largacha JA, Lusby M, Hoopes CW. Ambulatory femoral venovenous extracorporeal membrane oxygenation with a dual-lumen cannula. J Thorac Cardiovasc Surg Tech. 2021;9: 199-201. 